\title{
Factors associated with Integrated Counselling and Testing Center (ICTC) service satisfaction: experience from Chandigarh, India
}

\author{
Mahesh Devnani $^{1}$, Anil K Gupta ${ }^{1}$, Ajay Wanchu ${ }^{2}$, Rakesh K Sharma ${ }^{1}$ \\ ${ }^{1}$ Department of Hospital Administration, Post Graduate Institute of Medical Education and Research \\ (PGIMER), Chandigarh India \\ ${ }^{2}$ Department of Medicine, Oregon Health and Science University (OHSU), Portland, USA
}

\section{Correspondence \\ Dr. Mahesh Devnani \\ Department of Hospital \\ Administration, Post Graduate \\ Institute of Medical Education and \\ Research (PGIMER), Chandigarh \\ India}

Email: devnaniji@gmail.com

DOI: $10.3126 /$ jcmsn.v13i1.15752 http://dx.doi.org/

Article received: Sept $20^{\text {th }} 2016$ Article accepted: Feb $24^{\text {th }} 2017$

\begin{abstract}
Background \& Objectives: People while availing services at Integrated Counselling and Testing Centers (ICTC) face a lot of administrative and procedural problems which affect their level of satisfaction. This study was conducted at ICTC, Post Graduate Institute of Medical Education and Research, Chandigarh; within the scope of a larger research evaluating the "Quality of Infrastructure and Services available to PLHA"; to analyze the user's perception about quality of services and factors affecting satisfaction level. Materials \& Methods: Exit interviews of 50 randomly selected ICTC clients were conducted with structured questionnaire containing five groups of questions and questions on waiting time and satisfaction level. A scoring system was devised. The satisfaction level was cross matched with group questions.

Results: The mean group scores of five groups of questions were: Information, access \& guidance for services $(42.5 \%)$, Behaviour of counsellors (94\%), Quality of counselling (77.28\%), Physical facilities $(65.5 \%)$, Confidentiality, discrimination and grievance redressal $(67 \%)$. All respondents said that counsellors were respectful and $91 \%$ found the behaviour of counsellor supportive \& helpful, $80 \%$ reported that they understood everything that counsellor said. Eighty percent rated satisfaction level as satisfactory or above (6\% very satisfactory, $74 \%$ satisfactory), $18 \%$ indifferent and $2 \%$ very dissatisfied. Factors found to be associated with client satisfaction level were counsellor's response to the concerns and worries of clients up to their satisfaction $(\mathrm{p}=0.009)$, illumination in ICTC $(\mathrm{p}=0.04)$, knowledge of grievance redressal system $(p=0.04)$ and total time spent in ICTC $(p=0.03)$. Conclusion: This study provided user's perspective about ICTC service and revealed the factors associated with ICTC service satisfaction level. Better quality ICTC Services can be provided by addressing these factors.
\end{abstract}

Key words: AIDS; Counselling; HIV; ICTC; testing

Citation: Devnani M, Gupta AK, Wanchu A, Sharma RK. Factors associated with Integrated Counselling and Testing Center (ICTC) service satisfaction: experience from Chandigarh, India. JCMS Nepal. 2017;13(1):229-34.

\section{INTRODUCTION}

Human immunodeficiency virus (HIV) testing has been a cornerstone of HIV prevention efforts since 1985 when an accurate and reliable test for the HIV antibody became available. ${ }^{1}$ HIV counselling and testing services were started in India in 1997. Under National AIDS control programme -III (NACP-III) of India, Voluntary Counselling and Testing Centres (VCTC) and facilities providing Prevention of Parent to Child Transmission of HIV/AIDS
(PPTCT) services are remodelled as a hub or 'Integrated Counselling and Testing Centre' (ICTC) to provide services to all clients under one roof. ${ }^{2}$ There are more than 5,135 Counselling and Testing Centres in India (December, 2009) where more than six million general clients and 4.4 million pregnant women were counselled and tested as of December $2009 .^{3}$

Only thirteen percent of HIV positive people in India are aware of their HIV status. The challenge is 
to make all HIV infected people in the country aware of their status so that they adopt a healthy lifestyle; access life-saving care and treatment and help prevent further transmission of HIV. Thus, ICTC services are important components of prevention and control of HIV/AIDS in India. ${ }^{4}$

Human satisfaction is a complex concept that is related to a number of factors including life style, past experiences, future expectations and the value of both individual and society. Because satisfaction is a derived concept, it is important to find out the sources of dissatisfaction. Thus, in the present day context, evaluation of services from patient's point of view is becoming increasingly important component of health care delivery. ${ }^{5}$ Although high levels of patient satisfaction are important for a successful strategy against HIV/AIDS, research into satisfaction with ICTC services has been limited in India. Hence, this study was conducted to analyze ICTC service satisfaction among users and factors associated with satisfaction level, as part of a larger study "Evaluation of infrastructure and services available to PLHA" between July 2007 and December 2008 at PGIMER, Chandigarh. ${ }^{6}$

\section{MATERIALS AND METHODS}

For this prospective study, fifty clients were randomly recruited at ICTC, PGIMER, Chandigarh. Exit interviews were conducted with structured questionnaire prepared in consultation with clinical psychologist and according to the services available in the institute and local needs; with the help of National AIDS Control Organisation's (NACO) operational guidelines for ICTC (July 2007), ${ }^{2}$ and NACO's client satisfaction survey-voluntary counselling \& testing operational guidelines 2004 . $^{7}$ A pilot testing of questionnaire was done and based on findings, questionnaire was modified. Prior consent was obtained from all participants. The questionnaire contained following five groups of questions and questions on waiting time and satisfaction level:
A. Information, Access and Guidance for Services - two questions.
B. Behaviour of Counsellors - four questions.
C. Quality of Counselling - seven questions.
D. Physical Facilities - five questions.
E. Confidentiality, Discrimination and Grievance Redressal - five questions.

The analysis of the data was done by using descriptive statistical techniques. SPSS 16.0 (SPSS Inc., Chicago, USA) was used for all kind of data analysis. Independent Samples t test (for 2 groups) and oneway ANOVA (for $>2$ groups) were used to test the significance. A scoring system was devised:

- All questions were scored between -2 to +2 for all participants depending on the response of participant.

- The mean Question score of all questions was calculated by taking average of the scores of all participants for that particular question.

- The "Group Score" of each group for each participant was calculated by adding the scores given to all questions in that particular group by each participant.

- The mean "Group Score" of each group was calculated by taking average of "Group Scores" of all participants for that particular group.

- "Total Questionnaire score" of each participant was calculated by adding "Group Scores" of all groups of that participant.

- The mean "Total Questionnaire Score" (henceforth called "Total Questionnaire Score" only) was calculated by taking average of "Total Questionnaire score" of all participants.

Various factors associated with questionnaire score were analysed. The individual question score, group scores and total questionnaire score of individual participants/groups were compared with the level of satisfaction of participants to know the factors associated with the participant's satisfaction. Mean time spent in various activities was calculated and was compared with the level of satisfaction of participants. The study was approved by institute review committee and ethics committee.

\section{RESULTS}

\section{Socio-demographic profile}

There were 40 male and 10 female participants (Table 1). The mean age of participants was 35.48 years $(\mathrm{SD}=12.74)$ with minimum of 16 years and maximum of 78 years. Eighty two percent participants were below 45 years of age. The highest number of participants $(32 \%)$ was in the age group of 36 to 45 years. Fifty five percent of males and $60 \%$ of females were in the age group between 26 to 45 years. There were equal number of participants ( 25 each) from rural and urban areas. A total of $86 \%$ participants were literate. Fifty eight percent participants were having more than primary level and $26 \%$ participants were having more than secondary level education. There was no Illiterate female. Majority of participants $(60 \%)$ were married and were living with spouse. 
Table 1: Socio-demographic profile

Characteristics N N
Sex

$\begin{array}{lr}\text { Male } & 40 \\ \text { Female } & 10\end{array}$

Age (years)

$\begin{array}{lc}\leq 25 & 13 \\ 26 \text { to } 35 & 12 \\ 36 \text { to } 45 & 16 \\ >45 & 9\end{array}$

Place of

residence

$\begin{array}{ll}\text { Rural } & 25 \\ \text { Urban } & 25\end{array}$

Education

\begin{tabular}{|c|c|c|}
\hline & Illiterate & 7 \\
\hline & Literate to Primary & 14 \\
\hline & $\begin{array}{l}\text { >Primary to } \\
\text { Secondary }\end{array}$ & 16 \\
\hline & $>$ Secondary & 13 \\
\hline \multicolumn{3}{|l|}{ Occupation } \\
\hline & Agriculture & 10 \\
\hline & Driver/Cleaner & 5 \\
\hline & $\begin{array}{l}\text { Skilled/factory } \\
\text { worker/labourer }\end{array}$ & 9 \\
\hline & Service/Professional & 6 \\
\hline & Businessman & 2 \\
\hline & House Maker & 7 \\
\hline & Student & 5 \\
\hline & Others $^{\mathrm{a}}$ & 6 \\
\hline \multicolumn{3}{|l|}{ Marital status } \\
\hline & Never Married & 14 \\
\hline & $\begin{array}{l}\text { Married and Living } \\
\text { with spouse }\end{array}$ & 30 \\
\hline & $\begin{array}{l}\text { Married but not } \\
\text { Living with spouse }\end{array}$ & 3 \\
\hline & Spouse Died & 3 \\
\hline
\end{tabular}

${ }^{a}$ Others include Unemployed, Retired personnel, NGO worker.

\section{Source of information about ICTC services (multiple answers)}

Referral from health providers (42) was the main source of information followed by media (9) and peers/friends (6). Others included relatives (4) and information at own workplace (3).
Reasons for coming to ICTC (multiple answers)

Thirty six participants came to ICTC because it was related to their illness. Sixteen participants came due to issues arouse from an HIV test done some time ago and 14 participants came to know their HIV status. Others included: suspect I may be HIV infected (7), wanted information on HIV/AIDS (4), came for counselling on HIV (2).

\section{ICTC Questionnaire Score}

Total ICTC questionnaire Score of five groups was $20.58(\mathrm{SD}=9.00)$ on the scale of -46 to +46 which was $72.37 \%$ (Table 2). The question group "Behaviour of counsellors" scored highest (94\%), whereas the question group "Information, Access \& Guidance for Services" scored lowest (42.5\%). Although the total score of males (21.50) was higher than females (17.30) and total score of clients from urban areas (22.44) was higher than clients from rural areas (18.88), the Socio demographic profile of clients was not found to be significantly associated with the ICTC total questionnaire score.

Though ninety percent respondents said that there were not enough signage to guide, eighty percent respondents didn't face any difficulty in locating ICTC. All respondents said that counsellors were respectful, 99\% said that counsellor didn't criticize their behaviour and $91 \%$ found the behaviour of counsellor supportive \& helpful. All respondents were comfortable during the counselling session and $80 \%$ respondents understood everything counsellor said. However four percent respondents said that they didn't understand everything that counsellor said. Eighty percent respondents said that counsellor gave them enough time to ask questions but only $54 \%$ respondents said that counsellor encouraged them to ask questions. Sixty eight percent respondents felt that counsellor responded to their concerns and worries satisfactorily. Twenty six percent respondents said that counsellor didn't discuss with them the ways to prevent infection, and only $38 \%$ respondents said that counsellor discussed meaning of HIV positive and HIV negative results and possible implications. The mean score for cleanliness $(1.04,76 \%)$ was the highest among the group on the scale of -2 to +2 , followed by sitting arrangement (0.74), drinking water (0.48), lights (0.54) and sanitation/toilets (0.30).

Sixty four percent respondents said that counsellor assured them confidentiality but only $42 \%$ 
Table 2: ICTC Questionnaire Score

\begin{tabular}{|c|c|c|c|}
\hline Group & Scale & $\begin{array}{l}\text { Mean Group Score } \\
\text { (SD) }\end{array}$ & $\begin{array}{c}\text { Mean Group Score } \\
(\%)\end{array}$ \\
\hline $\begin{array}{l}\text { Information Access \& Guidance for } \\
\text { Services }\end{array}$ & -4 to +4 & $-0.60(1.82)$ & (I) \\
\hline Behaviour of Counsellors & -8 to +8 & $7.04(1.82)$ & 94 \\
\hline Quality of Counselling & -14 to +14 & 7.64 (4.97) & 77.28 \\
\hline Physical Facilities & -10 to +10 & $3.10(2.54)$ & 65.5 \\
\hline $\begin{array}{l}\text { Confidentiality, Discrimination \& } \\
\text { Grievance Reddressal }\end{array}$ & -10 to +10 & $3.40(3.08)$ & 67 \\
\hline ICTC Total questionnaire Score & -46 to +46 & $20.58(9.00)$ & 72.37 \\
\hline
\end{tabular}

\begin{tabular}{|c|c|c|c|c|}
\hline \multicolumn{5}{|c|}{ Table3: ICTC service satisfaction and ICTC questionnaire scores } \\
\hline \multicolumn{5}{|c|}{$\begin{array}{c}\text { Group Scores of ICTC Clients with different } \\
\text { level of satisfaction }\end{array}$} \\
\hline $\begin{array}{l}\text { Question } \\
\text { Groun }\end{array}$ & V. Satisfied & Satisfied & Indifferent & $\mathrm{P}$ \\
\hline & Mean (SD) & Mean (SD) & Mean (SD) & \\
\hline A & $0.00(0.00)$ & $-0.65(1.89)$ & $-0.67(2.00)$ & 0.84 \\
\hline B & $8.00(0.00)$ & $7.08(1.80)$ & $7.11(1.45)$ & 0.67 \\
\hline $\mathrm{C}$ & $10.00(4.00)$ & $8.32(4.80)$ & $5.33(4.36)$ & 0.18 \\
\hline $\mathrm{D}$ & $4.67(0.58)$ & $3.14(2.69)$ & $2.22(2.17)$ & 0.34 \\
\hline E & $4.67(4.16)$ & $3.51(3.18)$ & $2.89(2.47)$ & 0.69 \\
\hline Total & $27.33(5.50)$ & $21.41(8.52)$ & $16.89(9.82)$ & 0.17 \\
\hline
\end{tabular}

respondents were confident that the staff would not share information about them, including the test results. More than half $(56 \%)$ of the respondents said they can't say about this. Fourteen percent respondents said that there were other clients near during counselling who could hear what client or the counsellor was saying. Seventy four percent respondents didn't know where to talk/complain in case they had any grievance and only four percent respondents (all males) knew exactly where to go in case of any grievance.

The mean total time spent in ICTC was 56.40 minutes $(\mathrm{SD}=38.13)$. The age, sex and location of clients were not found to be significantly associated with the time spent in ICTC. However females were spending more time than males and clients from rural areas were spending more time than clients from urban areas.

\section{ICTC service satisfaction}

A total of $80 \%$ participants rated level of satisfaction as satisfactory or above, $(6 \%$ "very satisfied", 74\% "satisfied"), 18\% rated "indifferent" and $2 \%$ participants were "very dissatisfied". The mean ICTC s score on the scale -2 to 2 was 0.82 $(\mathrm{SD}=0.61,70.5 \%)$.

\section{Factors associated with ICTC service} satisfaction

As there was only one dissatisfied participant, it was excluded from analysis as "Post Hoc Multiple Comparisons" could not be done if one group has fewer than 2 cases. The difference in group totals and total ICTC Questionnaire score, among clients with different level of satisfaction was not significant (Table 3).

Four factors were found to be significantly associated with the ICTC service satisfaction. The difference in mean scores of very satisfied, satisfied and indifferent clients for "Do you feel that counsellor responded to your concerns and worries satisfactorily?" was statistically significant $(p=0.009)$. The knowledge about where to talk/ complain in case of grievance was also found to be significantly associated with ICTC service satisfaction as those who had higher mean scores 
for this variable, were more satisfied $(p=0.04)$. Physical facility (Lighting) was found to significantly influence the ICTC service satisfaction. The difference in mean scores of very satisfied, satisfied and indifferent clients was statistically significant $(p=0.04)$. The total time spent in ICTC was found to be significantly associated with the satisfaction level of clients $(\mathrm{p}=0.03)$.

\section{DISCUSSION}

It has been reported that the primary reasons for seeking HIV counselling and testing are: recent knowledge about HIV, current illness, self assessment of risky behaviour, and previous blood transfusion among others. ${ }^{8-9}$ We found the current illness as the most common reason to seek ICTC services followed by HIV test done some time ago, and self-assessment of risky behaviour. More than $80 \%$ participants were referred by health care workers. This could be because, ICTC was located in a tertiary care hospital near ART center and its clientele were already having some or other health related issue. The overall satisfaction level of ICTC clients for infrastructure and services of ICTC, PGIMER, Chandigarh was high as $80 \%$ participants rated level of satisfaction as "Satisfactory" or above. A survey conducted by Florida department of Health in 2006, showed that $95.1 \%$ of clients were "very satisfied" or "satisfied" with CLT (Counselling, Testing and Linkage) services, and only $0.5 \%$ respondents were "Very Dissatisfied" or "Dissatisfied". ${ }^{10}$ A study from Egypt reported that more than $90 \%$ of clients were satisfied with the voluntary counselling and testing (VCT) services. ${ }^{9}$

In the present study, signage display emerged as a weakness as $90 \%$ respondents said that there were not enough signage to guide patients to the ICTC. However study didn't find any association between "information, access and guidance for services" and the difference in level of ICTC client satisfaction.

The behaviour of counsellors emerged as a very strong point of ICTC, though it was not significantly associated with client satisfaction level. No respondent reported any problem with the behaviour of counsellors. But counsellor's satisfactory response to client's queries and worries was significantly associated with client satisfaction as the clients who felt that their queries were satisfactorily responded by counsellor were more satisfied than those who felt that their queries were not satisfactorily responded by counsellor. Illumination was also significantly associated with the level of satisfaction. The ICTC room was originally built for "X-Ray" room and it does not have even a single window. Sanitation/toilets emerged as a weakness as mean score was only $57.5 \%$. The mean score for sitting arrangement was also low. Some participants complained that the number of chairs was less and they had to remain standing. This was because the waiting area was a common area shared by ART center, ICTC and Pharmacy. The total time spent in ICTC was also found to be significantly associated with the satisfaction level of clients $(p=0.03)$. Those who spent more time in ICTC were less satisfied. Many participants reported that center was not opened on time and they had to wait unnecessarily.

As only four percent respondents knew exactly where to go in case of any grievance this emerged as a factor significantly associated with the satisfaction level of participants. In a study conducted in Egypt, ${ }^{9}$ male sex and higher education were associated with higher VCT service satisfaction whereas our study did not find any association between socio-demographics of participants and ICTC service satisfaction. In a study conducted at labs conducting HIV related testing in Tanzania, patients were not satisfied with waiting time, privacy, result notification, cleanliness and timely instructions. ${ }^{11}$

In reviewing a Public Interest Litigation (PIL), Hon'ble Supreme court of India said “....The State Governments shall strictly abide by NACO policies and guidelines regarding Counselling. Counselling will be done in a meaningful manner, spending time on each individual PLHA in an atmosphere that provides privacy and confidentiality" (Office Memorandum, T-11020/29/1998/NACO (Admn ART) dated 26th Aug 2008, NACO, India). But $14 \%$ respondents in this study said that there were other clients near during counselling who could hear what client or the counsellor was saying. The space for counselling was not divided into chambers to maintain the privacy during counselling. There was one cabin but was not in use as according to counsellors it small and not appropriate for counselling. The maintenance of privacy during counselling was difficult because both the counsellors (male and female) were sitting side by side in a single open room.

The findings of this study should be interpreted in view of some limitations as inherent in such surveys. It has long been observed that patient satisfaction surveys consistently report high levels of satisfaction as patients hide a variety of negative 
experiences. ${ }^{12}$ Also the possibility of recall bias in participant's responses cannot be ruled out. Because of small sample size and one location, the findings of this study should not be generalised. Also, as it is a cross sectional design, it could not measure the evolution of satisfaction over time and no causal relationship be established.

\section{CONCLUSION}

The study provides user's perspective about ICTC service and revealed the factors associated with ICTC service satisfaction level. Better quality ICTC services can be provided by addressing these factors.

\section{ACKNOWLEDGEMENTS}

The authors sincerely thank the participants for their time and energy in sharing their views and experiences; and staff member of ART and ICTC center for their cooperation especially Dr Archna B. Mohan \& Dr. Neeru Sharma. We gratefully acknowledge the technical and statistical inputs of Shivi Negi and Dr. P K Gupta.

\section{REFERENCES}

1. Worthington C, Myers T. Desired Elements of HIV Testing Services: Test Recipient Perspectives. AIDS Patient Care STDS. 2002;16(11):537-48. DOI: 10.1089/108729102761041092. PMID: 12513902.

2. National AIDS Control Organisation of India. Operational Guidelines for Integrated Counselling \& Testing Centres. New Delhi, 2007. Available from http://www.naco.gov.in/ sites/default/files/20\%2C\%20Operational $\% 20$ Guidelines $\%$ 20 for $\% 20$ Integrated $\% 20$ Counseling $\% 20$ and $\% 20$ Testing $\%$ 20Centres.pdf.

3. National AIDS Control Organisation of India. Annual report 2009-10. New Delhi, 2010. Available from http:// www.naco.gov.in/sites/default/files/NACO_AR_English\% 202009-10_NEW.pdf.

4. National A IDS Control Organisation of India [http:// www.nacoonline.org].

5. Verma A, Sarma RK. Evaluation of the "Exit Proformas" in use at Special Wards of a Public Sector Tertiary Care Hospital. J Acad Hosp Adm. 2000;12(1):23-7.

6. Devnani M, Gupta AK, Wanchu A, Sharma RK. Factors associated with health service satisfaction among people living with HIV/AIDS: a cross sectional study at ART center in Chandigarh, India. AIDS Care. 2012;24(1):100-7. DOI: 10.1080/09540121.2011.592816. PMID: 21767229

7. National AIDS Control Organisation of India. Client satisfaction survey-Voluntary counselling \& testing Operational guidelines. New Delhi, 2004.

8. Jereni BH, Muula AS. Availability of supplies and motivations for the accessing voluntary HIV counselling and testing services in Blantyre, Malawi. BMC Health Serv Res. 2008;8:17. DOI: 10.1186/1472-6963-8-17. PMID: 18215263.

9. Kabbash IA, Hassan NM, Al-Nawawy AN, Attalla AA Mekheimer SI. Evaluation of HIV voluntary counselling and testing services in Egypt. Part 1: client satisfaction. East Mediterr Health J. 2010;16(5):481-90. PMID: 20799546.

10. Bureau of HIV/AIDS, Florida Department of Health. State- wide client satisfaction survey report. Florida city, 2006.

11. Mfinanga SG, Kahwa A, Kimaro G, Kilale A, Kivuyo S, Senkoro M, et al. Patient's dissatisfaction with the public and private laboratory services in conducting HIV related testing in Tanzania. BMC Health Serv Res. 2008;8:167. DOI: 10.1186/1472-6963-8-167. PMID: 18687113.

12. Collins K, O'Cathain A. The continuum of patient satisfaction-from satisfied to very satisfied. Social Science \& Medicine. 2003;57(12):2465-70. DOI: 10.1016/S02779536(03)00098-4. 